\title{
Human Forearm Metabolism during Progressive Starvation
}

\author{
O. E. Owen and George A. Reichard, Jr. \\ From the Fels Research Institute and General Clinical Research Center, \\ Temple University School of Medicine and Smith, Kline \& French \\ Laboratories, Philadelphia, Pennsylvania 19140
}

A B S T R A C T Forearm muscle metabolism was studied in eight obese subjects after an overnight, 3 and 24 day fast. Arterio-deep-venous differences of oxygen, carbon dioxide, glucose, lactate, pyruvate, free fatty acids, acetoacetate, and $\beta$-hydroxybutyrate with simultaneous forearm blood flow were measured. Rates of metabolite utilization and production were thus estimated. Oxygen consumption and lactate and pyruvate production remained relatively constant at each fasting period. Glucose, initially the major substrate consumed, showed decreased consumption after 3 and 24 days of fasting. Acetoacetate and $\beta$-hydroxybutyrate consumption after an overnight fast was low. At 3 days of fasting with increased arterial concentrations of acetoactate and $\beta$-hydroxybutyrate, consumption of these substrates rose dramatically. At 24 days of fasting, despite further elevation of arterial levels of acetoacetate and $\beta$-hydroxybutyrate, the utilization of acetoacetate did not increase further and if anything decreased, while five out of eight subjects released $\beta$-hydroxybutyrate across the forearm. Acetoacetate was preferentially extracted over $\beta$-hydroxybutyrate. At 24 days of starvation, free fatty acids were the principal fuels extracted by forearm muscle; at this time there was a decreased glucose and also ketone-body consumption by skeletal muscle.

\section{INTRODUCTION}

Tissues preferentially utilize a fuel for oxidative metabolism depending on its arterial concentration, its availability relative to that of other substrates, and the hormonal milieu. Because progressive starvation markedly changes the blood levels of available fuels and hormones $(1-4)$, caloric deprivation for weight reduction may be employed to examine the effects of altered substrate presentation on human forearm muscle metabolism. Andres et al. (5) have described a forearm preparation

Dr. Owen is a George Morris Piersol Teaching and Research Scholar, American College of Physicians.

Received for publication 10 August 1970 and in revised form 16 February 1971. which is under normal physiologic control and permits quantitative measurement of substrate utilization or production.

Glucose consumption by muscle diminishes with fasting $(6,7)$ and indirect data suggest that acetoacetate $(\mathrm{AcAc})^{1}$ and $\beta$-hydroxybutyrate $(\beta$-OHB) are not major substrates for muscle metabolism after prolonged starvation (4).

In vitro studies using cardiac, striated, or diaphragmatic muscle tissue indicate that free fatty acids (FFA), AcAc, and/or $\beta$-OHB are oxidized preferentially to glucose and lactate (8-12). However, the competitive interplay among FFA, AcAc, and $\beta$-OHB by muscle under physiologic conditions has not been well defined.

The purpose of this study was to delineate the patterns of substrate consumption and/or production by muscle tissue in the forearm of man undergoing prolonged starvation for weight reduction. More specifically, it was our aim not only to determine the interplay between fatty acid and carbohydrate substrates, but also to quantitate the selective consumption by muscle of FFA, $\mathrm{AcAc}$, and $\beta$-OHB with changing arterial concentrations of these substrates.

\section{METHODS}

Subjects. Eight obese volunteers were selected for admission to the General Clinical Research Center of the Temple University Hospital (Table I). Before admission each subject was informed of the procedure planned and the potential risks involved in both starvation and forearm catheterization. During the prestarvation period, all subjects had normal hemograms, urinalyses, and serum-thyroxine levels. Of serum enzymes (alkaline phosphatase, lactic dehydrogenase, and glutamic oxaloacetate transaminase), only I. J. had an elevated SGOT before starvation. The electrocardiogram of J. C. showed a complete right bundle-branch block, B. J. showed left ventricular hypertrophy, and L. J. showed left axis deviation and evidence of old lateral ven-

${ }^{1}$ Abbreviations used in this paper: AcAc, acetoacetate; $\mathrm{A}-\mathrm{V}$, arteriovenous differences; $\mathrm{BF}$, blood flow; $\beta-\mathrm{OHB}$, $\beta$-hydroxybutyrate; FFA, free fatty acids; GC, glucose consumption; L, lactate production; SGOT, glutamic oxaloacetate transaminase. 
TABLE I

Clinical Data*

\begin{tabular}{|c|c|c|c|c|c|c|c|c|c|}
\hline \multirow[b]{2}{*}{ Subject } & \multirow[b]{2}{*}{ Age } & \multirow[b]{2}{*}{ Sex } & \multirow[b]{2}{*}{ Height } & \multicolumn{3}{|c|}{ Weight } & \multirow[b]{2}{*}{ Loss } & \multirow[b]{2}{*}{ I.V.G.T.T. $\ddagger$} & \multirow[b]{2}{*}{ Diagnoses } \\
\hline & & & & Initial & Final & Difference & & & \\
\hline & $y r$ & & $\mathrm{~cm}$ & $k g$ & $k g$ & $k g$ & $\%$ & $k_{q}$ & \\
\hline R. S. & 22 & M & 200.7 & 134.5 & 117.3 & 17.2 & 12.8 & 1.5 & Obesity \\
\hline J. C. & 54 & M & 181.6 & 153.6 & 138.2 & 15.4 & 10.0 & 0.8 & $\begin{array}{l}\text { Obesity } \\
\text { Polycythermia vera } \\
\text { Diabetes mellitus }\end{array}$ \\
\hline I. J. & 59 & $\mathbf{M}$ & 169.9 & 105.0 & 90.9 & 14.1 & 13.4 & 0.5 & $\begin{array}{l}\text { Obesity } \\
\text { Diabetes mellitus }\end{array}$ \\
\hline C. B. & 26 & $\mathrm{~F}$ & 160.5 & 108.6 & 96.4 & 12.2 & 11.2 & 1.1 & Obesity \\
\hline B. I. & 32 & $\mathrm{~F}$ & 158.8 & 127.5 & 111.4 & 16.1 & 12.6 & 1.8 & $\begin{array}{l}\text { Obesity } \\
\text { Asthma }\end{array}$ \\
\hline B. J. & 34 & $\mathrm{~F}$ & 159.4 & 128.4 & 111.6 & 16.8 & 13.1 & 1.2 & $\begin{array}{l}\text { Obesity } \\
\text { Hypertensive cardiovascular } \\
\quad \text { disease with left heart failure }\end{array}$ \\
\hline C. M. & 38 & $\mathrm{~F}$ & 156.2 & 86.8 & 76.8 & 10.0 & 11.5 & 0.5 & $\begin{array}{l}\text { Obesity } \\
\text { Diabetes mellitus }\end{array}$ \\
\hline L. J. & 57 & $\mathrm{~F}$ & 162.6 & 160.5 & 138.6 & 21.9 & 13.6 & 0.9 & $\begin{array}{l}\text { Obesity } \\
\text { Congestive heart failure } \\
\text { Diabetes mellitus }\end{array}$ \\
\hline
\end{tabular}

* All subjects underwent total caloric starvation for 24 days.

$\ddagger$ Intravenous glucose tolerance test $(0.5 \mathrm{~g} / \mathrm{kg})$ performed before weight reduction. Values expressed as absolute per cent disappearance per min.

tricular wall fibrosis. The chest X-ray of B. J. showed evidence of cardiac enlargement with pulmonary vascular congestion and L. J. showed an enlarged heart and pulmonary vasculature. All other electrocardiograms and chest X-rays were within normal limits.

During a prestarvation period of 5-7 days, subjects were fed a $2500 \mathrm{kcal}$ per day diet consisting of $300 \mathrm{~g}$ carbohydrate, $100 \mathrm{~g}$ protein, and $85 \mathrm{~g}$ fat. After baseline blood was obtained, an intravenous glucose-tolerance test was performed in each subject. Glucose ( $0.5 \mathrm{~g} / \mathrm{kg}$ body weight) was infused intravenously and blood was drawn for analysis at 10 min intervals for $1 \mathrm{hr}$ and then at 90 and $120 \mathrm{~min}$. I. J. and C. M. were known diabetics at the time of admission (Table I) and their oral hypoglycemic agents were withheld before starvation.

Daily intake during starvation consisted of one multivitamin capsule (Unicap, The Upjohn Company, Kalamazoo, Mich.), $17 \mathrm{mEq}$ of $\mathrm{NaCl}$ (sugar-free tablets), $1500 \mathrm{ml}$ of water, and as tolerated $13 \mathrm{mEq} \mathrm{KCl}$ (gelatin capsules).

Techniques for studying forearm metabolism. The ZuntzFick principle has been applied to the measurement of the exchange of metabolites between blood and muscle tissue of forearm $(13,14)$. In this study, forearm blood flow, volume (determined by water displacement), and arteriovenous differences of energy-yielding substrates and respiratory gases were measured after an overnight, 3 and 24 day-fasting period.

Catheterization, blood flow, and blood sampling. The brachial artery was cannulated with a Cournand needle (No. 16) placed percutaneously pointing proximal from the antecubital crease. A polyethylene catheter (I.D. 0.031) was inserted through and approximately 4 inches beyond the Cournand needle point. Arterial blood samples were obtained from the proximal tip of this double-lumen device,
$0.9 \%$ sterile saline containing Evans blue dye, U.S.P. T1824, was infused at a constant rate of $0.123 \mathrm{ml}$ per min by a motor-driven syringe and through the lumen formed between the polyethylene catheter and Cournand needle. Blood flow was calculated by the continuous dye dilution technique (5). A retrograde polyethylene catheter (I.D. 0.031) was inserted as deeply as possible through a large antecubital vein until the tip could no longer be palpated. In questionable instances, the position of the catheter was determined from X-rays. Venous-effluent blood was thus predominantly from muscle. After the venous catheter was in place, the arm tourniquet was removed.

Approximately $30 \mathrm{~min}$ after the dye infusion was initiated and exactly 5 min before the first blood sampling, blood flow through the wrist and hand was excluded by positioning a pediatric blood pressure cuff $(9 \mathrm{~cm}$ wide) about the wrist and inflating it to $100 \mathrm{~mm} \mathrm{Hg}$ above the subjects' systolic blood pressure. After blood sampling, the cuff was deflated for $10 \mathrm{~min}$. The cycle was repeated at $15 \mathrm{~min}$ intervals. Excluding the circulation through the wrist and hand, thus diminishing blood flow through the forearm, magnified the arteriovenous differences, and made them more easily detectable. Blood samples were drawn simultaneously during a $30-60 \mathrm{sec}$ timed interval from the arterial and deep venous catheters. An average of three arteriovenous blood collections was completed.

Chemical analysis of blood. Immediately after withdrawal, $10 \mathrm{ml}$ of blood was injected into a $10 \mathrm{ml}$ of icecold $1 \mathrm{M}$ perchloric acid and mixed. After centrifugation at $4^{\circ} \mathrm{C}$, supernatant portions were analyzed as quickly as possible for pyruvate by standard enzymatic techniques (15). The remaining supernatant was stored overnight at $-20^{\circ} \mathrm{C}$. AcAc and $\beta$-OHB were measured by a modification of the method of Williamson, Mellanby, and Krebs (3, 
TABLE II

Precision of Analytical Determinations

\begin{tabular}{|c|c|c|c|c|c|c|c|c|c|c|c|c|}
\hline \multirow[b]{2}{*}{ Metabolite } & \multirow[b]{2}{*}{ Oxygen } & \multirow{2}{*}{$\begin{array}{l}\text { Carbon } \\
\text { dioxide }\end{array}$} & \multirow[b]{2}{*}{ Glucose } & \multirow[b]{2}{*}{ Lactate } & \multirow[b]{2}{*}{ Pyruvate } & \multirow[b]{2}{*}{ FFA } & \multicolumn{3}{|c|}{ AcAc } & \multicolumn{3}{|c|}{$\beta-\mathrm{OHB}$} \\
\hline & & & & & & & Overnight & 3 Day & 24 Day & Overnight & 3 Day & 24 Day \\
\hline Mean \pm SEM & 4.41 & 22.02 & 3.74 & 0.570 & 0.098 & 0.751 & 0.111 & 0.269 & 1.790 & 0.187 & 2.074 & 4.742 \\
\hline & \pm 0.14 & \pm 0.12 & \pm 0.008 & \pm 0.008 & \pm 0.001 & \pm 0.002 & \pm 0.004 & \pm 0.002 & \pm 0.019 & \pm 0.002 & \pm 0.003 & \pm 0.022 \\
\hline
\end{tabular}

16). Lactate was estimated by standard enzymatic techniques (17). Blood glucose was determined by the Technicon (Technicon Corp., Tarrytown, N. Y.) autoanalyzer glucose oxidase-peroxidase procedure of Hill and Kessler (18) as modified by Steiner, Goodman, and Treble (19). All enzymatic analyses were done in duplicate except those for glucose, which were done in triplicate. Plasma FFA were determined in duplicate by the method of Dole and Meinertz (20). Oxygen and carbon dioxide contents were measured manometrically by a modification of the method of van Slyke and Neill $(21,22)$. Insulin concentrations were determined in duplicate by the double antibody radioimmunoassay of Morgan and Lazarow (23) as modified by Soeldner and Slone (24).

The precision of the analytical determinations for the metabolites is given in Table II. The concentrations of oxygen, carbon dioxide, glucose, lactate, pyruvate, and FFA from a venous blood sample were determined 10 times and the values are expressed as the mean \pm sem. Values for overnight, 3 day, and 24 day fast, derived and determined 10 times from three different venous blood samples, are given for AcAc and $\beta$-OHB because of the marked changes in concentrations for these substrates as starvation progresses.

Calculations. (a) Rates of extraction and/or production were derived by combining regional blood flow (BF) with arteriovenous differences $(\mathrm{A}-\mathrm{V})$ and are expressed as micromoles $/ 100 \mathrm{ml}$ of forearm per min.

(b) Plasma flow was converted to blood flow (BF) by the formula : blood flow = plasma flow $/ 1$ - hematocrit. Plasma FFA values were converted to blood FFA values by the formula: blood FFA value = plasma FFA value $(1-$ hematocrit).

(c) Calculation of the consumption of an extracted substrate to $\mathrm{CO}_{2}$ and $\mathrm{H}_{2} \mathrm{O}$ must take into account other byproducts of metabolism. Also, since approximately 2-3\% of forearm volume is probably occupied by mature erythrocytes (5) which derive their energy from glycolysis of glucose to lactate, at least part of the extracted glucose and lactate production is due to blood cells as they transverse the forearm. To prevent a gross overestimate of glucose consumption (GC), lactate production (L) was considered. Glucose consumption was estimated from the formula :

$$
\mathrm{GC}=\left\{\mathrm{G}(\mathrm{A}-\mathrm{V})-\frac{\mathrm{L}(\mathrm{V}-\mathrm{A})}{2}\right\} \times \mathrm{BF} .
$$

(d) Per cent extraction of AcAc and $\beta$-OHB was calculated by the equation $\mathrm{A}-\mathrm{V} / \mathrm{A} \times 100$, where $\mathrm{A}$ was the arterial and $\mathrm{V}$ the venous concentration of either substrate entering or leaving the forearm.

\section{RESULTS}

Arterial respiratory gases, substrates, and insulins. Table III shows the arterial oxygen, carbon dioxide, glucose, lactate, pyruvate, FFA, AcAc, and $\beta$-OHB, and serum insulin concentrations during progressive starvation. The oxygen, lactate, and pyruvate concentrations which remained relatively constant throughout the fast are comparable to those in overnight-fasted subjects and the decreased $\mathrm{CO}_{2}$ concentration observed at 3 and 24 days is consistent with the ketoacidosis of starvation $(14,25-27)$ and as given in White, Handler, and Smith (28), and as reviewed by Oliva (29). Glucose was decreased after 3 or 24 days of fasting. FFA rose significantly during the first 3 days of fasting $(P<0.05)$. However, the slight further increase in FFA observed at 24 days of fasting was not significant when com-

TABLE III

Arterial Respiratory Gases, ${ }^{*}$ Substrates, ${ }^{*}$ and Insulin $\ddagger$

\begin{tabular}{lrrrrrrrrr}
\hline & Oxygen & $\begin{array}{c}\text { Carbon } \\
\text { dioxide }\end{array}$ & Glucose & Lactate & Pyruvate & FFA & AcAc & $\beta$-OHB & Insulin \\
\hline Overnight & 7.56 & 22.43 & 5.42 & 0.625 & 0.064 & 0.511 & 0.106 & 0.185 & 30.8 \\
& \pm 0.47 & \pm 0.90 & \pm 0.73 & \pm 0.081 & \pm 0.009 & \pm 0.056 & \pm 0.011 & \pm 0.017 & \pm 4.7 \\
3 Day Fast & 7.40 & 20.56 & 3.69 & 0.657 & 0.052 & 0.729 & 0.829 & 2.233 & 15.8 \\
& \pm 0.51 & \pm 1.11 & \pm 0.50 & \pm 0.05 & \pm 0.007 & \pm 0.081 & \pm 0.124 & \pm 0.329 & \pm 2.1 \\
24 Day Fast & 7.23 & 18.07 & 3.53 & 0.553 & 0.050 & 0.841 & 1.515 & 5.291 & 11.5 \\
& \pm 0.31 & \pm 1.29 & \pm 0.17 & \pm 0.036 & \pm 0.004 & \pm 0.088 & \pm 0.117 & \pm 0.466 & \pm 2.2 \\
\hline
\end{tabular}

* Values, expressed in millimoles/liter of whole blood, are the mean \pm SEM.

$\ddagger$ Values are expressed in microunits/milliliter of serum, mean \pm SEM. 
pared to day $3(P>0.05)$. The concentrations of AcAc and $\beta-\mathrm{OHB}$ after an overnight fast in our obese subjects are comparable to other subjects reported in the literature $(3,16,30)$. The expected marked rise of $\mathrm{AcAc}$ and $\beta$-OHB with progressive starvation was observed with a maximum at 24 days of starvation. The inverse relationship between ketonemia and glycemia in starving individuals is well established. The overnight fasting serum-insulin concentration fell precipitously during the first 3 days of fasting with a further decrease noted after 24 days of starvation (4).
Blood flow and arteriovenous differences. Restingforearm blood flows during progressive starvation are shown in Table IV. The data after an overnight fast are in good agreement with those previously published $(5,31-33)$. The small, statistically insignificant increase in blood flow after fasting probably reflects the loss of forearm volume. After an overnight fast, the average forearm volume, measured from above the sphygmomanometer cuff to the antecubital crease, was $1373 \mathrm{ml}$ which decreased to an average of $1223 \mathrm{ml}$ after 24 days of fasting.

TABLE IV

Blood Flow* and A-DV Difference $\pm \mathrm{SE} \ddagger$

\begin{tabular}{|c|c|c|c|c|c|c|c|c|c|}
\hline Subject & Blood flow & $\mathrm{O}_{2}$ & $\mathrm{CO}_{2}$ & Glucose & Lactate & Pyruvate & FFA & AcAc & $\beta$-OHB \\
\hline \multicolumn{10}{|c|}{ Overnight fast } \\
\hline R. S. & 3.2 & 2.70 & -1.77 & 0.14 & -0.177 & 0.006 & 0.010 & 0.038 & 0.031 \\
\hline J. C. & 3.8 & 4.46 & -2.99 & 0.57 & -0.089 & 0.011 & -0.026 & 0.052 & 0.030 \\
\hline I. J. & 2.7 & 4.66 & -3.93 & 0.24 & -0.096 & 0.012 & -0.027 & 0.025 & 0.018 \\
\hline C. B. & 2.8 & 2.61 & -1.78 & 0.21 & -0.122 & 0.000 & 0.062 & 0.060 & 0.026 \\
\hline B. I. & 3.0 & 2.98 & -1.61 & 0.10 & -0.038 & 0.014 & 0.092 & 0.074 & 0.044 \\
\hline B. J. & 6.0 & - & - & 0.42 & -0.133 & -0.005 & 0.019 & 0.040 & 0.040 \\
\hline C. M. & 5.2 & 1.31 & -1.78 & 0.46 & -0.204 & 0.003 & 0.026 & 0.010 & -0.024 \\
\hline L. J. & 3.7 & 1.97 & -3.25 & 0.11 & -0.083 & -0.007 & 0.080 & 0.041 & 0.013 \\
\hline Mean $\pm \mathrm{SE}$ & 3.8 & 2.96 & -2.44 & 0.28 & -0.118 & 0.004 & 0.030 & 0.043 & 0.022 \\
\hline & \pm 0.42 & \pm 0.46 & \pm 0.35 & \pm 0.06 & \pm 0.019 & \pm 0.003 & \pm 0.016 & \pm 0.007 & \pm 0.008 \\
\hline \multicolumn{10}{|l|}{3 Day fast } \\
\hline R. S. & 4.4 & 2.18 & -2.77 & 0.02 & -0.075 & -0.010 & 0.005 & 0.203 & 0.067 \\
\hline J. C. & 4.3 & 4.12 & -3.27 & 0.10 & -0.167 & 0.007 & -0.024 & 0.270 & 0.174 \\
\hline I. J. & 3.2 & 2.64 & -2.28 & 0.22 & -0.176 & 0.010 & 0.051 & 0.254 & -0.075 \\
\hline C. B. & 3.0 & - & - & 0.19 & -0.188 & 0.006 & 0.059 & 0.341 & 0.196 \\
\hline B. I. & 3.8 & 1.58 & -0.63 & 0.17 & -0.100 & 0.015 & -0.012 & 0.203 & 0.164 \\
\hline B. J. & 5.7 & - & - & 0.02 & -0.113 & -0.005 & 0.114 & 0.123 & 0.054 \\
\hline C. M. & - & - & - & - & - & - & - & - & - \\
\hline L. J. & - & 0.23 & -0.99 & 0.17 & -0.073 & 0.009 & 0.097 & 0.078 & 0.065 \\
\hline \multirow[t]{2}{*}{ Mean $\pm \mathrm{SE}$} & 4.1 & 2.15 & -1.99 & 0.13 & -0.127 & 0.005 & 0.041 & 0.2108 & 0.092 \\
\hline & \pm 0.40 & \pm 0.64 & \pm 0.51 & \pm 0.03 & \pm 0.018 & \pm 0.003 & \pm 0.020 & \pm 0.034 & \pm 0.036 \\
\hline \multicolumn{10}{|l|}{24 Day fast } \\
\hline R. S. & 4.2 & 3.45 & -1.92 & 0.16 & -0.085 & 0.017 & 0.048 & 0.179 & 0.304 \\
\hline J. C. & 4.6 & 3.17 & -2.73 & 0.03 & -0.111 & -0.009 & 0.083 & 0.269 & -0.133 \\
\hline I. J. & 2.4 & 2.76 & -2.39 & -0.03 & -0.075 & 0.008 & 0.063 & 0.355 & -0.898 \\
\hline C. B. & 3.8 & 4.95 & -2.83 & 0.20 & -0.092 & -0.002 & 0.094 & 0.234 & 0.160 \\
\hline B. I. & 3.9 & 1.81 & -1.87 & 0.16 & -0.120 & 0.001 & 0.099 & 0.039 & -0.232 \\
\hline B. J. & 5.0 & - & - & 0.04 & -0.091 & -0.005 & 0.034 & 0.062 & 0.428 \\
\hline C. M. & 6.4 & 1.51 & -0.85 & 0.07 & -0.100 & 0.007 & 0.044 & 0.022 & -0.283 \\
\hline L. J. & 4.7 & 1.51 & -2.23 & 0.18 & -0.090 & 0.006 & 0.062 & 0.202 & -0.043 \\
\hline \multirow[t]{2}{*}{ Mean \pm SE } & 4.4 & 2.74 & -2.12 & 0.10 & -0.096 & 0.003 & 0.0668 & $0.170 \S$ & -0.087 \\
\hline & \pm 0.40 & \pm 0.47 & \pm 0.25 & \pm 0.03 & \pm 0.005 & \pm 0.003 & \pm 0.008 & \pm 0.042 & \pm 0.146 \\
\hline
\end{tabular}

The release of a metabolite is indicated by a - sign.

* Blood flow is expressed as milliliters $/ 100 \mathrm{ml}$ of forearm/minute.

$\ddagger$ Metabolites are expressed as millimoles/liter of whole blood.

$\S P<0.05$ compared with overnight fasting values. 
The arterio-deep-venous differences for oxygen, carbon dioxide, glucose, lactate, pyruvate, FFA, AcAc, and $\boldsymbol{\beta}$-OHB are also presented in Table IV. After an overnight, 3 day or 24 day fast, all subjects extracted oxygen, AcAc, and glucose (except I. J. at 24 days) and produced carbon dioxide and lactate. The arterio-deep-venous differences in FFA levels are difficult to assess since their release from adjacent adipose tissue is quite variable relative to the rate of FFA removal by muscle tissue (34-36). Furthermore, intramuscular-lipid stores may provide muscle with fatty acids directly without transport through the plasma (37). However, these sources of contamination are probably curtailed by extended starvation. The mean net extractions of FFA observed at the overnight and the 3 day fasting periods may have been fortuitous. However, at 24 days the extraction was significantly different from zero $(P<$ 0.05) (Table IV). There was a significant net uptake of $\beta$-OHB after the overnight fast in all subjects except in one of the known diabetic subjects, C. M. Unfortunately, catheterization attempts on C. M. were unsuccessful after the 3 day fast. Only I. J., the other known diabetic subject, showed a net release of $\beta$-OHB after the 3 day fast. After the 24 day fast three subjects extracted $\beta-\mathrm{OHB}$. and five subjects, four of whom were diabetic, consistently released $\beta$-OHB across the deep forearm tissue. The mean net release of $\beta-\mathrm{OHB}$ by the forearm of these eight subjects was not statistically significant when compared with the overnight or 3 day fast. However, this lack of statistical significance arises primarily from the fact that there were large individual variations among the subjects.

The per cent extraction of arterial AcAc and $\beta-\mathrm{OHB}$ decreased with progressive starvation. After an overnight fast, means of about $40 \%$ of arterial AcAc and $12 \%$ of arterial $\beta$-OHB were extracted. Therefore, the $\beta$-OHB/AcAc ratios in the arterial and venous blood differed. Hagenfeldt and Wahren (30) reported on A-V difference of about $50 \%$ for both AcAc and $\beta-O H B$ across the resting forearm muscle and, therefore, no alteration in arterial and venous ratio of these substrates

TABLE V

Metabolic Exchange $\pm \mathrm{SE}$ (umoles $/ 100 \mathrm{ml}$ forearm per min)*

\begin{tabular}{lrrr}
\hline Metabolite & \multicolumn{1}{c}{ Overnight } & \multicolumn{1}{c}{3 Day } & \multicolumn{1}{c}{24 Day } \\
\hline $\mathrm{O}_{2}$ & $9.788 \pm 1.400$ & $10.440 \pm 2.538$ & $11.189 \pm 1.809$ \\
$\mathrm{CO}_{2}$ & $-8.390 \pm 1.190$ & $-8.985 \pm 2.619$ & $-8.618 \pm 1.024$ \\
$\mathrm{~L}$ & $-0.473 \pm 0.112$ & $-0.533 \pm 0.061$ & $-0.423 \pm 0.048$ \\
G & $1.184 \pm 0.348$ & $0.425 \pm 0.109$ & $0.452 \pm 0.117$ \\
G-L/2 & $\mathbf{0 . 9 4 6} \pm 0.310$ & $0.160 \pm 0.110$ & $0.235 \pm 0.116$ \\
FFA & $0.107 \pm 0.052$ & $0.144 \pm 0.111$ & $0.278 \pm 0.033$ \\
AcAc & $0.153 \pm 0.024$ & $0.894 \pm 0.070$ & $0.660 \pm 0.144$ \\
$\beta$-OHB & $0.079 \pm 0.036$ & $0.387 \pm 0.145$ & $-0.208 \pm 0.524$ \\
\hline
\end{tabular}

* Expressed as whole blood values. was observed. However, their overnight fasting arterial AcAc and $\beta$-OHB concentrations were less than those shown in Table III. With the rising arterial concentrations observed at day 3 mean values of about $25 \%$ of AcAc and only $4 \%$ of $\beta-\mathrm{OHB}$ were extracted. After 24 days of fasting, about $11 \%$ of arterial AcAc was extracted while, on the average, there was a small increase in venous $\beta$-OHB over arterial $\beta$-OHB concentration. Although the arterial levels of $\beta$-OHB exceeded those of AcAc, the latter substrate was either preferentially consumed and/or converted in part into $\beta$-OHB by peripheral tissue. This difference in uptake and release thus alters the arterial and venous $\beta-\mathrm{OHB} / \mathrm{AcAc}$ ratios. Similar changes in the ratio of ketone-bodies has been demonstrated by in situ perfusion of the hind limb of the starving cat (38).

Rates of extraction and production. Calculated rates of extraction or production of respiratory gases and substrates are presented in Table V. There was no detectable reduction in oxygen requirements $/ 100 \mathrm{ml}$ of forearm by deep tissue (mainly muscle) in the resting state during prolonged fasting. At rest and with adequate oxygenation, deep-venous lactate concentration always exceeded arterial lactate concentration.

The mean glucose extraction diminished during starvation (Table V). Glucose consumption. which takes into account lactate production, apparently decreased by 3 days and remained low at 24 days. After an overnight fast, glucose consumption was $0.946 \mu \mathrm{moles} / \mathrm{min},{ }^{2}$ which exceeds that previously reported in nonobese subjects $(34,39)$. Rabinowitz and Zierler studied six obese subjects after an overnight fast and reported that the mean forearm-muscle extraction of glucose was about twice that of their nonobese controls. While their obese subjects were approximately $20 \%$ overweight (40), ours varied from 41 to $231 \%$ overweight (Table I). Furthermore, our obese subjects had a relative hyperinsulinemia as well as a hyperglycemia when compared to an age and sex matched, nonobese population studied in our laboratories (glucose $=4.46 \pm 0.14$ mmoles/liter, $\mathrm{n}=8$, and insulin $=16 \pm 2.8 \mu \mathrm{U} / \mathrm{ml}, \mathrm{n}=8)$. Christensen and Orskov (41) reported a highly significant correlation between muscle glucose uptake and simultaneous arterial-serum insulin concentration using the human forearm preparation. The degree of obesity and the accompanying hyperinsulinemia and hyperglycemia may in part be responsible for the observed differences.

After 3 days of fasting, the mean glucose extraction was decreased to $0.425 \mu \mathrm{moles} / \mathrm{min}$, a value apparently below that of an overnight fast $(1.18 \mu$ moles $/ \mathrm{min})$. Although a greater fraction of glucose extracted was accounted for by lactate production, there persisted a

${ }^{2}$ Hereafter, rates of exchange will be expressed as micromoles/min with $100 \mathrm{ml}$ of forearm understood. 
small net glucose consumption of $0.160 \mu \mathrm{moles} / \mathrm{min}$. In studies of four nonobese subjects fasted for $66 \mathrm{hr}$, Zierler and Rabinowitz (7) reported a similar uptake; however, glucose extraction was totally accounted for by lactate production. These differences are small and are probably due to the limited number of subjects investigated in both studies. After 24 days of fasting, glucose extraction was $0.452 \mu \mathrm{moles} / \mathrm{min}$, a value similar to that observed after 3 days of fasting, and apparently less than that obtained after an overnight fast. Felig, Pozefsky, Marliss, and Cahill (6) reported a similar fall in glucose extraction across the forearm of obese subjects after prolonged starvation. Glucose consumption at 24 days of starvation was estimated to be 0.235 $\mu \mathrm{moles} / \mathrm{min}$.

Extraction of AcAc and $\beta$-OHB was observed after the overnight fast. Although the fractional uptakes for AcAc and $\beta$-OHB were high (Tables II-IV), they were not major energy-yielding substrates due to their low arterial concentrations. In fact, only $0.153 \mu$ moles/ $\min$ of AcAc and $0.079 \mu$ moles $/ \mathrm{min}$ of $\beta$-OHB were extracted (Table $\mathrm{V}$ ). After 3 days of starvation, the arterial levels of AcAc and $\beta$-OHB had risen about 8and 12-fold, respectively, and $0.894 \mu \mathrm{moles} / \mathrm{min}$ of AcAc and $0.387 \mu$ moles $/ \mathrm{min}$ of $\beta-\mathrm{OHB}$ were extracted, indicating that these substrates were major respiratory fuels. After 24 days of fasting and a further 2-fold rise in arterial level, AcAc extraction was only 0.660 $\mu$ moles $/ \mathrm{min}$. Thus, in spite of an increase in arierial AcAc availability, the uptake did not increase any further, and if anything decreased. The increased uptake of AcAc at 3 and 24 days is statistically significant when compared to the overnight extraction $(P<0.05)$. Although a similar increase occurred in the arterial level of $\beta$-OHB there was a paradoxical net mean release of $0.208 \mu \mathrm{moles} / \mathrm{min}$ of this substrate across the forearm muscle after 24 days of starvation. Thus, forearm tissue (muscle) preferentially extracts AcAc over $\beta$-OHB during starvation ketosis.

The rapid reduction of AcAc to $\beta$-OHB has been known for many years (42), and the dehydrogenase responsible for this reaction has been localized in the mitochondrial cristae of many tissues, including liver, kidney, brain, and muscle (43). With high AcAc concentrations in the media, Williamson and Krebs (44), using the isolated-perfused rat heart, reported that the disappearance of AcAc was accompanied by the formation of $\beta-\mathrm{OHB}$, the amount being about half that of the AcAc removed. Bassenge et al. (45) reported similar findings from in vivo studies by determining arteriovenous differences across dog myocardium. Hagenfeldt and Wahren reported a net production of $\beta$-OHB from the exercising forearm muscle (30). Wiedemann and Krebs suggested that the ketogenic capacity of extra-

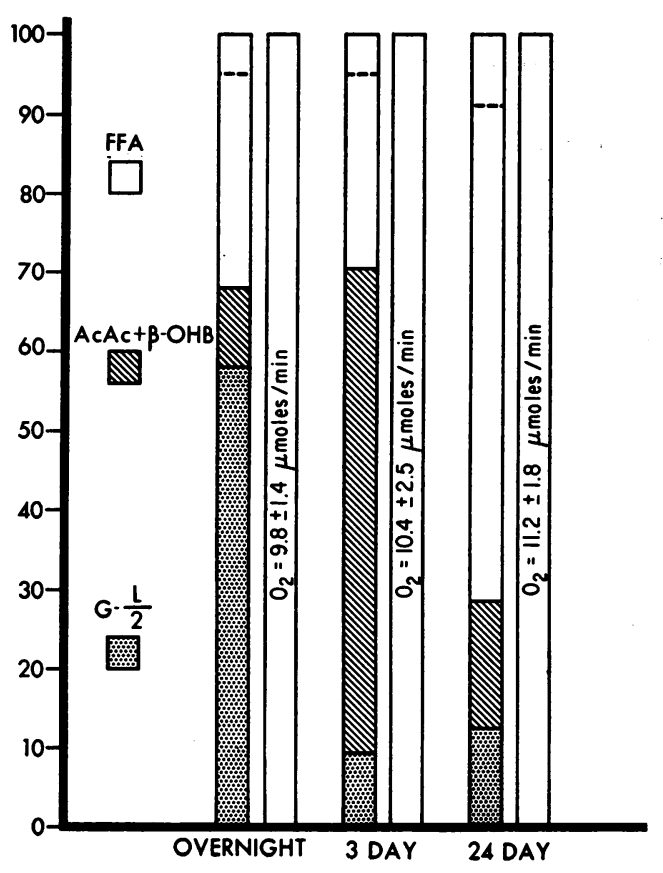

FIgURE 1 Oxygen equivalents, per cent of total uptake. Oxygen equivalents of extracted substrates expressed as per cent of total uptake for each fasting period. The open bar on the right gives the measured oxygen extraction. The space above the dashed-lines in each bar on the left represents the difference between the observed and calculated oxygen uptake. For purposes of calculation the following oxygen equivalents (micromole of $\mathrm{O}_{2}$ for micromole of substrate) were assumed: 6 for glucose, 4.0 for AcAc, 4.5 for $\beta-\mathrm{OHB}$, and 25 for FFA.

hepatic tissues is an inseparable aspect of their ability to utilize AcAc as a fuel of respiration (46). Once the enzymes required for AcAc utilization are sufficiently active, the ketogenic capacity of tissues can be manifested providing the concentration of acetyl CoA derived from FFA, pyruvate, or ketone-bodies is relatively high. It cannot be determined from this study whether there was de novo synthesis of $\beta-\mathrm{OHB}$ from acetyl-CoA or simple reduction of AcAc to $\beta$-OHB. However, there was a net release of $\beta$-OHB across the forearm muscle in five of eight subjects starved for 24 days.

Support for the possibility that there is altered consumption of glucose, AcAc, $\beta$-OHB, and FFA as starvation progresses can be obtained from a metabolic balance for each period. Table $\mathrm{V}$ presents the calculated mean values for metabolites removed or produced in micromoles $/ 100 \mathrm{ml}$ of forearm per min, and Fig. 1 presents the calculated oxygen equivalents in percentage of measured oxygen extraction needed for total combustion of these substrates to $\mathrm{CO}_{2}$. There is good agreement between the total calculated oxygen consumption 
and that determined directly and graphically represented in Fig. 1. Further support that there are changing patterns of substrate consumption as starvation progresses can be derived from calculating the mean respiratory quotients for each fasting period from the data in Table V. Respiratory quotients ( $R Q$ ) of 0.86 after the overnight fast and 0.86 after the 3 day fast, suggest that glucose and/or ketoacids are the major metabolic fuels at these times. A RQ of 0.77 after the 24 day fast implies that FFA are the major substrates. That there was an actual decreased consumption of glucose, AcAc, and $\beta$-OHB by forearm muscle after 24 days of starvation was suggested by the observation that there was a significant extraction of FFA across the deep forearm tissue at this time $(P<0.05)$, thus excluding the oxidation of other substrates. It is reasonable to assume that the extracted FFA are oxidized and not stored by deep forearm tissue during this catabolic state of prolonged starvation.

\section{DISCUSSION}

During the resting state, roughly $30 \%$ of total body oxidative metabolism occurs in the striated muscle mass of man. Thus, the fuels of respiration utilized by muscle are important in determining over-all body metabolism.

Forearm metabolism was investigated after an overnight, 3 and 24 day fasting period because these stages of starvation represent times when arterial substrate availability and serum insulin concentrations have changed drastically. A relatively constant metabolic steady state develops after about 24 days of starvation, when the concentrations of blood substrates and hormones are comparable on a day-to-day basis (4).

The changing patterns of substrate consumption by forearm muscle during progressive starvation are graphically illustrated in Fig. 1. After an overnight fast, glucose consumption accounted for about $58 \%$ of the oxygen uptake. During starvation the supply of glucose and of available gluconeogenic precursors is limited which necessitates that muscle derive its metabolic "fuels" from noncarbohydrate substrates (47). This is dramatically shown by a reduction in glucose uptake at 3 and 24 days of starvation, to amounts accounting for $9-13 \%$ of the extracted oxygen. These estimates of glucose uptake by muscle, when corrected only for lactate release, are probably in excess. Felig et al. (6) recently described a glucose-alanine-glucose cycle involving striated muscle that is analogous to the glucoselactate-glucose (Cori) cycle. In this cyclic process, the glucose extracted by muscle is glycolyzed to pyruvate which is then transaminated to alanine and released into the circulation for subsequent removal by the liver for glucose production. Thus, the quantity of lactate produced by blood cells (see section on Calculations under
Methods) as well as alanine released by muscle should be considered in calculations of glucose extraction and conversion to $\mathrm{CO}_{2}$ and $\mathrm{H}_{2} \mathrm{O}$.

Extensive investigations performed on normal weight subjects after an overnight fast have shown that the $\mathrm{RQ}$ of forearm muscle approached 0.7 , suggesting that long-chain fatty acids are major energy-yielding substrates. Recognizing the inherent difficulties in estimating FFA uptake of forearm muscle by means of chemical arteriovenous differences, Zierler. Maseri, Klassen, Rabinowitz, and Burgess (48) applied a method involving ${ }^{14} \mathrm{C}$-labeled fatty acid infusion and demonstrated that oleate and palmitate were major energy-yielding substrates of this tissue. The results of our study are in agreement with this observation. Whether calculated on the basis of the observed FFA extraction, or by difference between the observed $\mathrm{O}_{2}$ consumption minus that required for the combustion of glucose and ketonebodies, FFA accounted for $30-60 \%$ of the oxygen uptake indicating that this substrate was a preferred fuel for muscle metabolism, especially by 24 days of starvation.

After an overnight fast ketone-body uptake across forearm muscle accounted for about $10 \%$ of the extracted oxygen. At 3 days, concomitant with rising arterial levels, ketone-body uptake increased and accounted for about $51 \%$ of the oxygen uptake. After similar periods of starvation with comparable ketonemia, Gammeltoft (1) and Havel, Segel, and Balasse (49) reported that oxidation of AcAc plus $\beta-\mathrm{OHB}$ could account for $50-85 \%$ of the consumed oxygen across extremities of man. However, as "starvation diabetes" developed with further elevation of arterial levels of AcAc and $\beta$-OHB noted after 24 days of fasting, the apparent uptake of AcAc diminished, and there was a release of $\beta-\mathrm{OHB}$ in five of eight of the subjects. AcAc plus $\beta$-OHB accounted for only about $16 \%$ of the extracted oxygen. Weidemann and Krebs concluded that although FFA and ketone bodies compete as fuels, the preference for one over the other depended on their relative concentrations (46). In this study the arterial ketone-body concentrations exceeded that of FFA. However, the concentrations of competitive substrates at the intracellular sites of metabolism may not be reflected by their blood levels. Schonfeld and Kipnis (50) have shown that the FFA level in the diaphragm exceeded that in plasma after $96 \mathrm{hr}$ of starvation. It is, therefore, possible that the intracellular FFA concentration exceeded that of either AcAc or $\beta-O H B$ in these starving obese subjects.

Randle, Garland, Hales, and Newsholme have proposed a glucose-fatty acid cycle in which a reciprocal relationship exists between fatty acid and carbohydrate oxidation (10). From this study it is reasonable to 
speculate that after prolonged starvation fatty acid oxidation diminishes not only glucose, but also ketonebody utilization by skeletal muscle.

Ketone-body consumption by peripheral tissues can be estimated by combining substrate $\mathrm{A}-\mathrm{V}$ differences with estimated blood flow. In studying similar obese subjects with an average body weight of $108 \mathrm{~kg}$ after fasting 5-6 wk, Owen, Felig, Morgan, Wahren, and Cahill (4) reported cardiac output to be 4.8 liters $/ \mathrm{min}$. Of this output, 2.8 liters/min were required for brain, liver, and kidney. Therefore, no more than 4.8 liters/ min minus 2.8 liters $/ \mathrm{min}$ which equals 2 liters $/ \mathrm{min}$ could go to the remainder of the body. Furthermore, excluding blood flow through the hand and wrist with an inflated sphygomomanometer cuff should decrease blood flow through that extremity by approximately $50 \%,{ }^{8}$ magnifying $\mathrm{A}-\mathrm{V}$ differences 2 -fold. Thus, a reasonable extrapolation of blood flow to peripheral tissues under these circumstances is about 1 liter $/ \mathrm{min}$. If deep forearm-tissue metabolism (mainly muscle) is representative of peripheral tissues and it is assumed that the A-DV differences reported here are reasonably accurate. it can be calculated that after 24 days of starvation such tissues remove about $25 \mathrm{~g}$ of AcAc and add about $13 \mathrm{~g}$ of $\beta-\mathrm{OHB}$ to the blood stream daily, with a net ketone-body consumption of approximately $12 \mathrm{~g} /$ day. (Table III)."

Daily balance from measured values of $\beta$-OHB and AcAc are shown in Table VI. The estimated ketonebody production rate of $109 \mathrm{~g} /$ day can be compared to utilization rate of $112 \mathrm{~g} /$ day $(4,51)$. The discrepancy between AcAc and $\beta$-OHB production and utilization ratio may be due to temporal differences, since more AcAc is converted to $\beta-\mathrm{OHB}$ by peripheral tissues as starvation progresses.

After prolonged starvation, brain (51) and kidney (4) but not muscle, appear to be the principal sites of ketone-body utilization. Basso and Havel recently reported decreased utilization of ketone-bodies across the hind leg (mainly muscle) of depancreatinized dogs (52). Thus, there appears to be impaired ketone-body utilization by skeletal muscle in both prolonged starvation and depancreatinized diabetes.

In ketoacidotic diabetic patients, Kety, Polis, Nadler, and Schmidt (53) were unable to demonstrate ketone-

\footnotetext{
${ }^{8}$ Personal communication from Dr. K. L. Zierler, Department of Medicine, The Johns Hopkins Hospital, Baltimore, Md.

"Data were derived by multiplying the measured arteriodeep-venous differences for AcAc and $\beta$-OHB by the estimated peripheral blood flow of $1 \mathrm{liter} / \mathrm{min}$ and converting the values to a $24 \mathrm{hr}$ period. mmoles/24 hr were converted to $\mathrm{g} / 24 \mathrm{hr}$ using a mol wt of 102 for AcAc and 104 for $\beta$-OHB.
}

TABLE VI

Daily Ketone Body Balance after Prolonged Starvation*

\begin{tabular}{lcrcc}
\hline & $\beta$-OHB $¥$ & AcAc & $\begin{array}{c}\text { Duration of } \\
\text { starvation }\end{array}$ & Reference \\
\hline Splanchnic & -59 & -29 & $5-6 \mathrm{wk}$ & 4 \\
Renal & +49 & -8 & $5-6 \mathrm{wk}$ & 4 \\
Brain & +32 & +6 & $5-6 \mathrm{wk}$ & 51 \\
Muscle, etc. & -13 & +25 & $3-4 \mathrm{wk}$ & Th s study \\
& +9 & -6 & & \\
& +9 & & & \\
\hline
\end{tabular}

* Values are expressed in grams.

$\ddagger$ The release of $\beta$-OHB and AcAc is indicated by a - sign.

body utilization by brain. However, under these conditions glucose is present in overabundance, and, since glucose is the preferred fuel for the brain, it is unnecessary for this tissue to derive energy from ketonebody consumption. After determining the turnover rate and oxidation of ketone-bodies in normal and diabetic dogs, Balasse and Havel (54) concluded that impaired utilization of ketone-bodies contributes to diabetic ketoacidosis. Our data support this conclusion. If muscle is not the main consumer of ketone-bodies in diabetic states, then the accumulation of AcAc and $\beta-\mathrm{OHB}$ in uncontrolled diabetes mellitus could be due, at least in part, to the lack of removal of ketone-bodies by the brain of patients developing progressive diabetic ketoacidosis.

\section{ACKNOWLEDGMENTS}

The authors wish to express their appreciation to Mrs. P. James, Mrs. L. Cieslinski, Miss Maria Mozzoli, and Mr. E. Langdon for their technical assistance; to the nursing staff of the General Clinical Research Center at Temple University Hospital; and to Mrs. R. Masloff and Miss J. Green for their secretarial assistance.

This work was supported in part by Grants from U. S. Public Health Service Research Grant 5 M01 RR349-04, National Institutes of Health, General Clinical Research Centers Branch, and Smith, Kline \& French Laboratories.

\section{REFERENCES}

1. Gammeltoft, A. 1950. The significance of ketone-bodies in fat metabolism. I. Concentration of ketone bodies in the arterial and venous blood in human subjects during starvation. Acta. Physiol. Scand. 19: 270.

2. Drenick, E. J., M. E. Swendseid, W. H. Blahd, and S. G. Tuttle. 1964. Prolonged starvation as treatment for severe obesity. J. Amer. Med. Ass. 187: 100.

3. Cahill, G. F., M. G. Herrera, A. P. Morgan, J. S. Soeldner, J. Steinke, P. L. Levy, G. A. Reichard, Jr., and D. M. Kipnis. 1966. Hormone-fuel interrelationships during fasting. J. Clin. Invest. 45: 1751.

4. Owen, O. E., P. Felig, A. P. Morgan, J. Wahren, and G. F. Cahill, Jr. 1969. Liver and kidney metabolism during prolonged starvation. J. Clin. Invest. 48: 574. 
5. Andres, R., K. L. Zierler, H. M. Anderson, W. N. Stainsby, G. Cader, A. S. Ghrayyib, and J. L. Lilienthal, Jr. 1954. Measurement of blood flow and volume in the forearm of man; with notes of the theory of indicatordilution and on production of turbulence, hemolysis, and vasodilation by intra-vascular injection. J. Clin. Invest. 33: 482.

6. Felig, P., T. Pozefsky, E. Marliss, and G. F. Cahill, Jr. 1970. Alanine: key role in gluconeogenesis. Science (Washington). 167: 1003.

7. Zierler, K. L., and D. Rabinowitz. 1963. Roles of insulin and growth hormone, based on studies of forearm metabolism in man. Medicine (Baltimore). 42: 385.

8. Williamson, J. R., and H. A. Krebs. 1961. Acetoacetate as fuel of respiration in the perfused rat heart. Biochem J. 80: 540.

9. Shipp, J. C., L. H. Opie, and D. Challoner. 1961. Fatty acid and glucose metabolism in the perfused heart. Nature (London). 189: 1018.

10. Randle, P. J., P. B. Garland, C. N. Hales, and E. A. Newsholme. 1963. The glucose fatty-acid cycle: Its role in insulin sensitivity and the metabolic disturbances of diabetes mellitus. Lancet. $1: 785$.

11. Shipp, J. C. 1964. Interrelation between carbohydrate and fatty acid metabolism of isolated perfused rat heart. Metab. Clin. Exp. 13: 852 .

12. Randle, P. J., P. B. Garland, C. N. Hales, E. A. Newsholme, R. M. Denton, and C. I. Pogson. 1966. Interactions of metabolism and the physiological role of insulin. Recent Progr. Hormone Res. 22: 1.

13. Mottram, R. F. 1955. The oxygen consumption of human skeletal muscle in vivo. J. Physiol. (London). 128: 268.

14. Andres, R., G. Cader, and K. L. Zierler. 1956. The quantitatively minor role of carbohydrate in oxidative metabolism by skeletal muscle in intact man in the basal state. Measurements of oxygen and glucose uptake and carbon dioxide and lactate production in the forearm. J. Clin. Invest. 35: 671.

15. Bücher, T., R. Czok, W. Lampreicht, and E. Latzko. 1965. Pyruvate. In Methods of Enzymatic Analysis. H. Bergmeyer, editor. Academic Press Inc., New York. 2nd edition. 253.

16. Williamson, D. H., J. Mellanby, and H. A. Krebs. 1962. Enzymatic determination of $D(-)-\beta$-hydroxybutyric acid and acetoacetic acid in blood. Biochem. J. 82: 90.

17. Hohorst, H. J. 1965. L-(+)-Lactate. In Methods of Enzymatic Analysis. H. Bergmeyer, editor. Academic Press Inc., New York. 2nd edition. 266.

18. Hill, J. B., and G. Kessler. 1961. An automated determination of glucose utilizing a glucose oxidase-peroxidase system. J. Lab. Clin. Med. 57: 970.

19. Steiner, A. L., A. D. Goodman, and D. H. Treble. 1968. Effect of metabolic acidosis on renal gluconeogenesis in vivo. Amer. J. Physiol. 215: 211.

20. Dole, V. P., and H. Meinertz. 1960. Microdetermination of long-chain fatty acids in plasma and tissues. J. Biol. Chem. 235: 2595.

21. Peters, J. P., and D. D. van Slyke. 1932. In Quantitative Clinical Chemistry. The Williams \& Wilkins Co., Baltimore. 2: 229.

22. Lochhead, H. B., and M. K. Purcell. 1951. Some recent changes in blood gas methods applied to the Van Slyke volumetric apparatus. Amer. J. Clin. Pathol. 21: 177.

23. Morgan, C. R., and A. Lazarow. 1963. Immunoassay of insulin: two antibody system. Plasma insulin levels in normal, subdiabetic and diabetic rats. Diabetes. 12: 115.
24. Soeldner, J. S., and D. Slone. 1965. Critical variables in the radioimmunoassay of serum using the double antibody technic. Diabetes. 14: 771 .

25. Tranquada, R. E., W. J. Grant, and C. R. Peterson. 1966. Lactic acidosis. Arch. Intern. Med. 117: 192.

26. Wahren, J. 1966. Circulatory and metabolic response to different types of rhythmic isotonic exercise. Acta Physiologica Scand. 67 (Suppl.) : 46.

27. Reidenberg, M. M., B. L. Haag, B. J. Channick, C. R. Shuman, and T. G. G. Wilson. 1966. The response of bone to metabolic acidosis in man. Metab. (Clin. Exp.). $15: 236$.

28. White, A., P. Handler, and E. L. Smith. 1954. In Principles of Biochemistry. McGraw-Hill Book Company, New York. 4th edition.

29. Oliva, P. B. 1970. Lactic acidosis. Amer. J. Med. 48: 209.

30. Hagenfeldt, L., and J. Wahren. 1968. Human forearm muscle metabolism during exercise. III. Uptake, release and oxidation of $\beta$-hydroxybutyrate and observations on the $\beta$-hydroxybutyrate/acetoacetate ratio. Scand. J. Clin. Lab. Invest. 21: 314.

31. Cooper, K. E., O. G. Edholm, and R. F. Mottram. 1955. The blood flow in skin and muscle of the human forearm. J. Physiol. (London). 128: 258.

32. Butterfield, W. J. H., and H. E. Holling. 1959. Peripheral glucose metabolism in fasting control subjects and diabetic patients. Clin. Sci. (London). 18: 147.

33. Pozefsky, T., P. Felig, J. D. Tobin, J. S. Soeldner, and G. F. Cahill. 1969. Amino acid balance across tissues of the forearm in postabsorptive man. Effects of insulin at two dose levels. J. Clin. Invest. 48: 2273.

34. Baltzan, M. A., R. Andres, G. Cader, and K. I. Zierler. 1962. Heterogeneity of forearm metabolism with spacial references to free fatty acids. J. Clin. Invest. 41: 116.

35. Rabinowitz, D., and K. L. Zierler. 1962. Role of free fatty acids in forearm metabolism in man, quantitated by use of insulin. J. Clin. Invest. 41: 2191.

36. Hagenfeldt, L., and J. Wahren. 1968. Human forearm muscle metabolism during exercise. II. Uptake, release and oxidation of individual FFA and glycerol. Scand. J. Clin. Lab. Invest. $21: 263$.

37. Steinberg, D. 1966. Lipid stores as substrate elsewhere than in adipose tissue. In Proceedings of a Conference on Energy Metabolism and Body Fuel Utilization. Alfred P. Morgan, editor. Harvard University Press, Cambridge.

38. Gammeltoft, A. 1951 . The ratio of $\beta$-hydroxybutyric acid to acetoacetic acid in blood under various experimental conditions. Acta Physiol. Scand. 24: 35.

39. Zampa, G. A., F. Altilia, D. Bracchetti, G. D. Geminiani, E. Borgatti, and M. T. Odifreddi. 1967. Studies on peripheral glucose metabolism using the experimental human forearm preparation. Diabetologia. 3: 35 .

40. Rabinowitz, D., and K. L. Zierler. 1962. Forearm metabolism in obesity and its response to intra-arterial insulin. Characterization of insulin resistance and evidence for adaptive hyperinsulinism. J. Clin. Invest. 41: 2173.

41. Christensen, N. J., and H. Orskov. 1968. The relationship between endogenous serum insulin concentration and glucose uptake in the forearm muscles of nondiabetics. J. Clin. Invest. $47: 1262$.

42. Green, D. E., J. G. Dewan, and L. F. Leloir. 1937. The $\beta$-hydroxybutyric dehydrogenase of animal tissues. Biochem. J. $31: 934$. 
43. Lehninger, A. L., H. C. Sudduth, and J. B. Wise. 1960. The D- $\beta$-hydroxybutyric dehydrogenase of animal tissues. Biochem. J. $31: 934$.

44. Williamson, J. R., and H. A. Krebs. 1961. Acetoacetate as fuel of respiration in the perfused rat heart. Biochem. J. 80: 540.

45. Bassenge, E., V. E. Wendt, P. Schollmeyer, G. Blumchen, S. Gudbjarnason, and R. J. Bing. 1965. Effect of ketone bodies on cardiac metabolism. Amer. J. Physiol. 208: 162.

46. Weidemann, M. J., and H. A. Krebs. 1969. The fuel of respiration of rat kidney cortex. Biochem. J. 112: 149.

47. Cahill, G. F., Jr., O. E. Owen, and A. P. Morgan. 1968. The consumption of fuels during prolonged starvation. Advan. Enzyme Regul. 6: 143.

48. Zierler, K. L., A. Maseri, G. Klassen, D. Rabinowitz, and J. Burgess. 1968. Muscle metabolism during exercise. Trans. Ass. Amer. Physicians Philadelphia. 81: 266.

49. Havel, R. J., N. Segel, and E. O. Balasse. 1969. Effect of 5-methylpyrazole-3-carbozylic acid (MPCA) on tat metabolism, ketogenesis and glucose metabolism during exercise in man. Adv. Exp. Med. Biol. 4: 105.

50. Schonfeld, G., and D. M. Kipnis. 1968. Glucose-fatty acid interactions in the rat diaphragm in vivo. Diabetes. 17: 422.

51. Owen, O. E., A. P. Morgan, H. G. Kemp, J. M. Sullivan, M. G. Herrera, and G. F. Cahill, Jr. 1967. Brain metabolism during fasting. J. Clin. Invest. 46: 1589.

52. Basso, L. V., and R. J. Havel. 1970. Hepatic metabolism of free fatty acids in normal and diabetic dogs. J. Clin. Invest. 49: 537.

53. Kety, S. S., B. D. Polis, C. S. Nadler, and C. F. Schmidt. 1948. The blood flow and oxygen consumption of the human brain in diabetic acidosis and coma. $J$. Clin. Invest. $27: 500$.

54. Balasse, E. O., and R. J. Havel. 1970. Turnover rate and oxidation of ketone bodies in normal and diabetic dogs. Diabetologia. 6: 36 . 